\title{
EDITORIAL
}

\section{Top Cited Session: the best of RBP}

\author{
João Quevedo, ${ }^{1,2,3,4}$ Antonio E. Nardi ${ }^{5,6,7,8}$ \\ ${ }^{1}$ Translational Psychiatry Program, Department of Psychiatry and Behavioral Sciences, McGovern Medical School, The University of Texas \\ Health Science Center at Houston (UTHealth), Houston, TX, USA. ${ }^{2}$ Center of Excellence on Mood Disorders, Department of Psychiatry \\ and Behavioral Sciences, McGovern Medical School, UTHealth, Houston, TX, USA. ${ }^{3}$ Neuroscience Graduate Program, The University of \\ Texas MD Anderson Cancer Center UTHealth Graduate School of Biomedical Sciences, Houston, TX, USA. ${ }^{4}$ Laboratório de Psiquiatria \\ Translacional, Programa de Pós-Graduação em Ciências da Saúde, Universidade do Extremo Sul Catarinense (UNESC), Criciúma, SC, \\ Brazil. ${ }^{5}$ Faculdade de Medicina, Universidade Federal do Rio de Janeiro (UFRJ), Rio de Janeiro, RJ, Brazil. ${ }^{6}$ Academia Nacional de Medicina, \\ Rio de Janeiro, RJ, Brazil. ${ }^{7}$ Laboratório de Pânico \& Respiração, Ambulatório de Depressão Resistente, Instituto de Psiquiatria, UFRJ, Rio de \\ Janeiro, RJ, Brazil. ${ }^{8}$ Università Deglli Studi di Cagliari, Sardegna, Italy.
}

As we approach the XXXVI Congress of the Brazilian Psychiatric Association, which this year will take place in Brasilia from October 17th to 20th, we congratulate the authors of the articles published in Revista Brasileira de Psiquiatria (RBP) that have received the highest number of citations in 2017. We take this opportunity also to celebrate our latest impact factor (IF) of 2.093 (CJCR 2017, Clarivate Analytics). The new IF, which represents a slight increase from last year's score, gives us confidence that our work is being recognized and that we are heading in the right direction.

Following what has become a tradition during the Congress, the "top 10" original manuscripts and review studies will be presented in a special session, coordinated by the journal Editors. Among the original articles, the most cited paper in 2017 deals with the effects of using ayahuasca, an Amazonian psychoactive brew, to treat patients with recurrent depression. In an open-label trial led by researchers from the Department of Neurosciences and Behavior at the Ribeirão Preto Medical School, Universidade de São Paulo (USP), Brazil, and the National Science and Technology Institute for Translational Medicine, the study showed how a single dose of ayahuasca rapidly and significantly reduced depressive symptoms. ${ }^{1}$

In the review article category, the psychometric properties of the Beck Depression Inventory-II, published in 2013, once again ranked first in number of citations. ${ }^{2}$ New to this category is a meta-analysis by Schuch et al. focusing on the effects of exercise for depression in the elderly. ${ }^{3}$ The multinational team of researchers found that exercise had a large and significant effect on depression, particularly when exercise was of moderate intensity, group-based, mixing aerobic and anaerobic interventions.

Table 1 summarizes the most cited publications in 2017. We continue to receive a large sum of manuscripts, much above our publication capacity, making our rejection rate steady over $50 \%$. Since we migrated to the new submission system (ScholarOne Manuscripts hosted by SciELO), last December, we have received 213 new articles, from 21 countries. We will keep committed to publishing high quality and relevant papers in RBP, and thus, year after year, make the Top Cited Session a main attraction at the Congress of the Brazilian Psychiatric Association.

\section{Disclosure}

The authors report no conflicts of interest.

\section{References}

1 Osório FL, Sanches RF, Macedo LR, Santos RG, Maia-de-Oliveira $J P$, Wichert-Ana L, et al. Antidepressant effects of a single dose of ayahuasca in patients with recurrent depression: a preliminary report. Rev Bras Psiquiatr. 2015;37:13-20.

2 Wang YP, Gorenstein C. Psychometric properties of the Beck Depression Inventory-II: a comprehensive review. Rev Bras Psiquiatr. 2013; 35:416-31.

3 Schuch FB, Vancampfort D, Rosenbaum S, Richards J, Ward PB, Veronese $\mathrm{N}$, et al. Exercise for depression in older adults: a metaanalysis of randomized controlled trials adjusting for publication bias. Rev Bras Psiquiatr. 2016;38:247-54.

4 Campos AC, Fogaça MV, Aguiar DC, Guimarães FS. Animal models of anxiety disorders and stress. Rev Bras Psiquiatr. 2013;35 Suppl 2: S101-11.

5 Zuardi AW. Cannabidiol: from an inactive cannabinoid to a drug with wide spectrum of action. Rev Bras Psiquiatr. 2008;30:271-80.

6 Abelaira HM, Réus GZ, Quevedo J. Animal models as tools to study the pathophysiology of depression. Rev Bras Psiquiatr. 2013; 35 Suppl 2: S112-20.

7 Kunz M, Ceresér KM, Goi PD, Fries GR, Teixeira AL, Fernandes BS, et al. Serum levels of IL-6, IL-10 and TNF- $\alpha$ in patients with bipolar disorder and schizophrenia: differences in pro- and anti-inflammatory balance. Rev Bras Psiquiatr. 2011;33:268-74.

8 Moreira-Almeida A, Neto FL, Koenig HG. Religiousness and mental health: a review. Rev Bras Psiquiatr. 2006;28:242-50.

9 Zuardi AW. History of cannabis as a medicine: a review. Rev Bras Psiquiatr. 2006;28:153-7.

10 Gomes-Oliveira MH, Gorenstein C, Lotufo Neto F, Andrade LH, Wang YP. Validation of the Brazilian Portuguese version of the Beck Depression Inventory-II in a community sample. Rev Bras Psiquiatr. 2012;34:389-94.

11 Viana MC, Andrade LH. Lifetime Prevalence, age and gender distribution and age-of-onset of psychiatric disorders in the São Paulo Metropolitan Area, Brazil: results from the São Paulo Megacity Mental Health Survey. Rev Bras Psiquiatr. 2012;34:249-60.

12 Moreira FA, Crippa JA. The psychiatric side-effects of rimonabant. Rev Bras Psiquiatr. 2009;31:145-53.

13 Malloy-Diniz LF, Lasmar VA, Gazinelli LS, Fuentes D, Salgado JV. The Rey Auditory-Verbal Learning Test: applicability for the Brazilian elderly population. Rev Bras Psiquiatr. 2007;29:324-9.

14 Moreira-Almeida A, Koenig HG, Lucchetti G. Clinical implications of spirituality to mental health: review of evidence and practical guidelines. Rev Bras Psiquiatr. 2014;36:176-82.

15 Czepielewski L, Daruy Filho L, Brietzke E, Grassi-Oliveira R. Bipolar disorder and metabolic syndrome: a systematic review. Rev Bras Psiquiatr. 2013;35:88-93. 


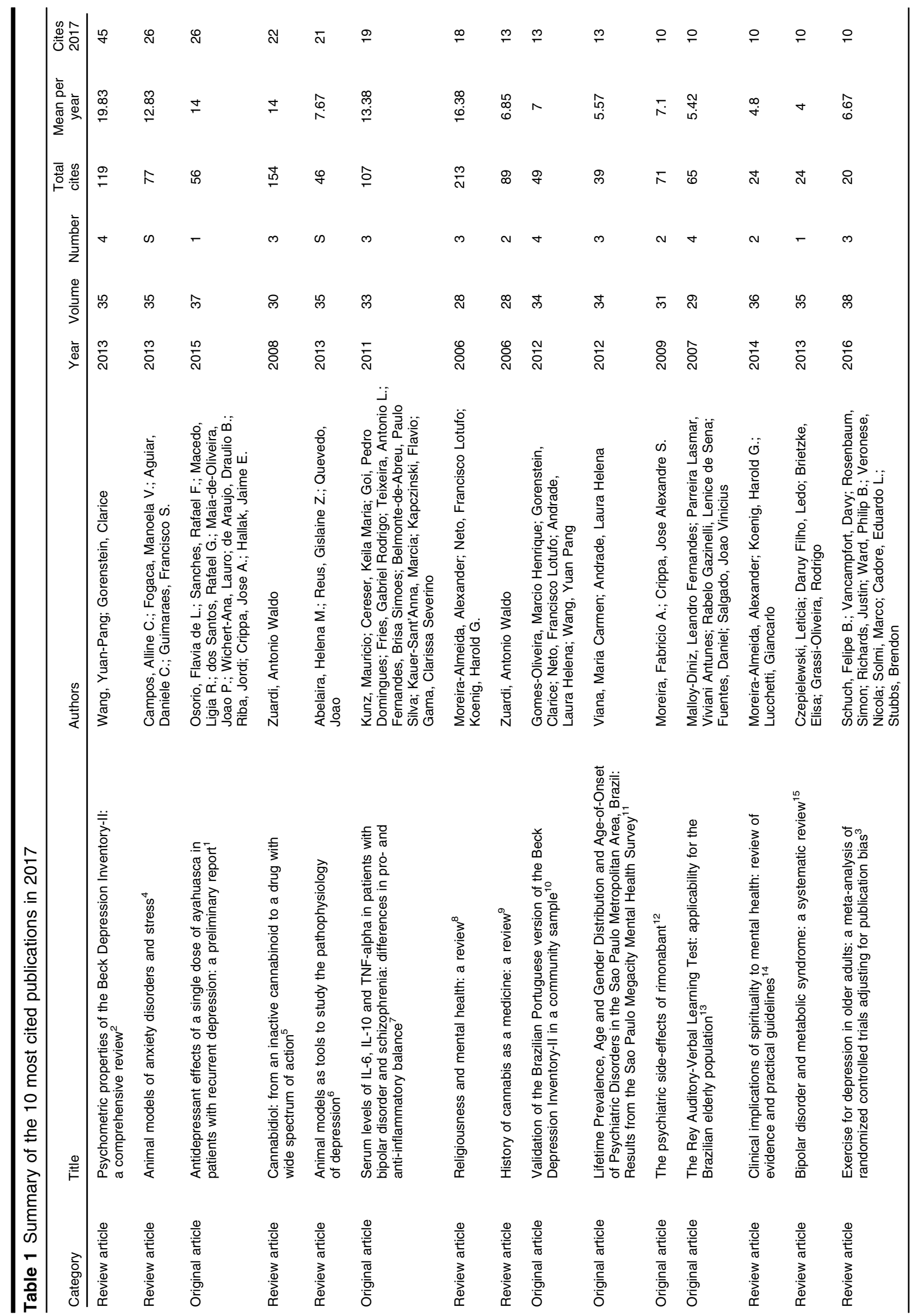

